\title{
A Novel Method for Nano-Polishing TEM Samples Out of a Ni-Ti Endodontic File
} \author{
Benamara ${ }^{1}$ and Z Ryan $\operatorname{Tian}^{1,2,3 *}$ \\ ${ }^{1}$ Institute of Nanoscience/Engineering, University of Arkansas, Fayetteville, AR 72701 \\ ${ }^{2}$ Chemistry and Biochemistry, University of Arkansas, Fayetteville, AR 72701 \\ ${ }^{3}$ Microelectronics-Photonics, University of Arkansas, Fayetteville, AR 72701 \\ ${ }^{4}$ Mechanical Engineering, University of Arkansas, Fayetteville, AR 72701 \\ ${ }^{5}$ Dentsply Sirona Endodontics, Tulsa, OK, USA, 74135-6537 \\ ${ }^{6}$ Dentsply Sirona Endodontics, Ballaigues, Switzerland, $\mathrm{CH}-1338$
}

Licheng Hua ${ }^{1,2}$, Abayomi Omolewu ${ }^{2,3}$, Nicholas Broadbent ${ }^{4}$, Charles Z Deng ${ }^{5}$, Janine L Conde ${ }^{6}$, Mourad

Submission: June 15, 2017; Published: June 23, 2017

*Corresponding author: Ryan Tian, Institute of Nanoscience/Engineering, University of Arkansas, Fayetteville, Arkansas, Email: rtian@uark.edu

\begin{abstract}
Specimen preparation of transmission electron microscopy (TEM) typically requires the use of focused ion beam (FIB) or ion milling. However, this FIB technology is too expensive, difficult to learn and operate, and time-consuming even for the users with extensive training and experience. Here we demonstrate a user-friendly mechanical method by simply using a tripod polisher for preparing TEM samples on alloyed oxide layer surface. Using this nano-polishing method, TEM specimen of endodontic files of nickel-titanium (Ni-Ti) alloy we repolished successfully.
\end{abstract}

Keywords: Tripod polisher; Nickel-titanium endodontic file; Angular adjustment

\section{Opinion}

Transmission electron microscopy (TEM) provides critical analyses of nano-scale structures [1,2] in especially nanomaterials science. To obtain reliable results from the TEM analysis, the samples must be thinned to electron transparency. This can be achieved conventionally by a combination of mechanical polishing and focused ion beam (FIB) [3] or ion milling [4]. The FIB is common equipment usually attached to a high-end scanning electron microscope (SEM) for TEM specimen preparation with its advantages and disadvantages [57]. For example, arte facts can be introduced during the sample preparation which may jeopardize the interpretation of the TEM data [8]. Besides the trouble in maintaining and using the expensive FIB-SEM, the techniques require special skills, and are time-consuming [8]. In particular, the regular mechanical polishing and FIB are both not good to analyze the different hue-color of oxides on the surface of the Ni-Tialloy endodontic file, since during the processes the oxide-layer's structure and composition can be altered. Thus, finding a user-friendly alternative for preparing especially the Ni-Tialloy sample with the much reduced cost and time can greatly benefit the users with the limited budget and time.
In this opinion, we demonstrated a new nano-polishing method for preparing the Ni-Tiendodontic file for TEM analysis by employing a low-cost mechanical polisher called Tripod Polisher (Model 590, South Bay Technology).In particular, the thin Ni-Tiendodontic file has aspiral (twisted) and tapered sharp tip see Figure $1 \mathrm{~A}$ at which the TEM-sample's preparation is quite difficult.

In experiment, this sample was first of all embedded in a mold filled with a self-setting polymeric resin, as showed in Figure 1A. There is in-molded sample was then cross-sectioned using a low-speed diamond saw. Next, the cross-sectioned file was mounted onto the polymer stub of the tripod polisher. Then, the stub was attached to the screw-micrometer for being gradually lowered down until the sample touches the abrasive surface (Figure 1B).

On this basis, sandpapers of ascending grit-sizes (400, 800 , and 1200 ) were iteratively applied onto the specimen for grinding, which produced a smooth surface. Then, likewise using diamond-polish paper with the grit-size ranging from 6 to 0.1 microns, the surface of the sample was polished further. The final 
polishing step on the same side of the specimen was performed using a mechano-chemical process with a water-solution of colloidal silica. After finishing this side, the sample was flipped over for grinding and polishing, as described above, to finally obtain a thin slab $(\sim 0.1 \mathrm{~mm})$.

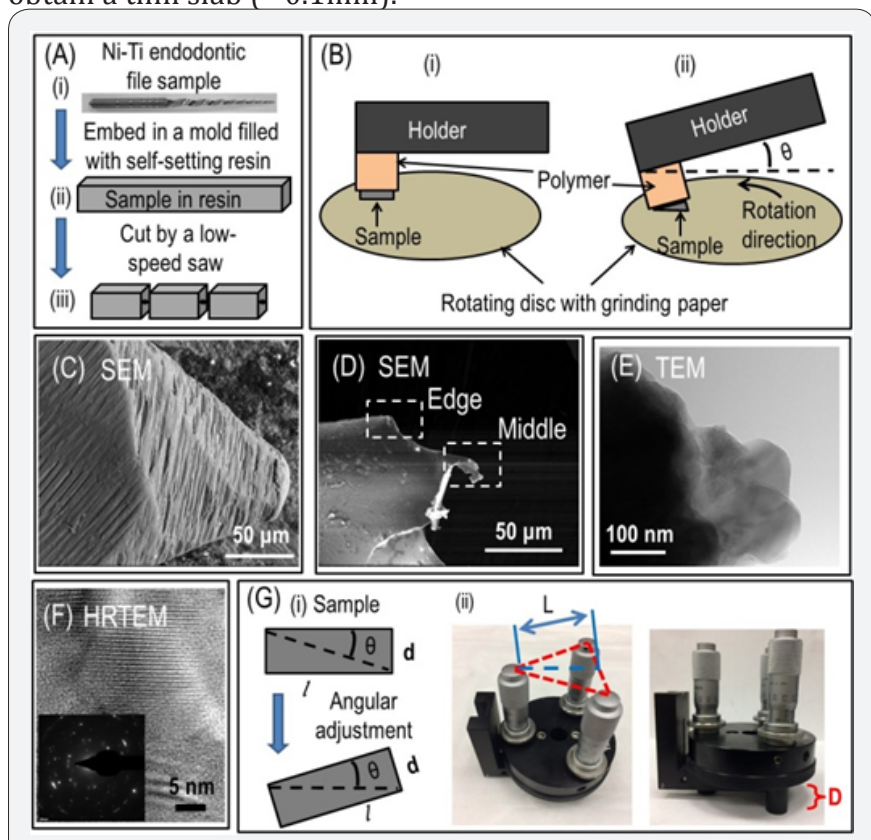

Figure 1: A demonstration of the proposed low-cost method for preparing the $\mathrm{Ni}-\mathrm{Ti}$ endodontic file in to TEM samples.

A. The Ni-Tiendodontic file sample was embedded into a mold filled with self-setting resin;

B. Schematic illustration of i) the first side and ii) the second side polishing process;

C. An SEM image for showing the surface-morphology of $\mathrm{Ni}$-Ti endodontic file;

D. An SEM image for $\mathrm{Ni}-\mathrm{Ti}$ endodontic file slice from the new nano-polishing method of the TEM sample;

E. TEM and High Resolution TEM (HRTEM) images of a $\mathrm{Ni}$-Ti sample from this new nano-polishing, showing clear crystal structure

F. TEM and High Resolution TEM (HRTEM) images of a Ni-Ti sample from this new nano-polishing, showing clear crystal structure

G. Schematic illustration of estimating the angular adjustment of the holder based on the thickness and length of the specimen by the trigonometric functions.

Thereafter, the angle of the holder was calculated (see equations below), and physically adjusted. Then, the thin-slab (on the tripod-polisher) was further polished by repeating the aforementioned steps (Figure 1B), until the tip was thinner than $100 \mathrm{~nm}$ for the ease of electron transmission for the TEM analysis [9]. To avoid overheating and dehydrating the sample to induce unwanted reactions on the sample-surface during the polishing, a water-cooling was used all the time.

The results from the SEM (FEI XL-30, Philips) and TEM study on the Ni-Ti sample were outlined in Figure 1C-1F. The SEM micrograph (Figure 1C) showed morphology of Ni-Ti endodontic file, and that of Figure 1D showed a transparent edge from the middle of the Ni-Ti sample slice. The images from the TEM analysis (FEI, TITAN 80-300) (Figure 1E \& 1F) showed a clear crystal lattice-structure of the Ni-Ti endodontic file. These results implied that the use of the low-cost tripod polisher for preparing the TEM sample out of the Ni-Ti endodontic file's spiral tip was effective.

The angular adjustment of the holder can be calculated based on the thickness (d) and length (l) of the specimen (Figure $1 \mathrm{G})$ via trigonometric function. The equations are shown in the (1) and (2) below, where, $d=$ the specimen's thickness (measure by screw micrometer); l=the specimen's length (measure by rule); $\theta=$ angle between holder base and horizontal axis; $D=$ the height the micrometer screw gauge need to lowered; $\mathrm{L}=$ the triangle's height from three screw micrometers see Figure 1G.

$$
\begin{aligned}
& \operatorname{Ta} n \theta=d / l \\
& D=L \times \operatorname{Tan} \theta=L \times d / l
\end{aligned}
$$

\section{Summary}

In summary, a user-friendly and simple angular adjustment using the low-cost tripod polisher enabled an effective and efficient method for preparing $\mathrm{Ni}-\mathrm{Ti}$ endodontic file TEM samples. This method has the proven versatility for reliably, reproducibly, and efficiently producing specimen of many types for TEM nano-analysis, which is ideal for new users with limited funds and time.

\section{References}

1. Buess G (1993) Review: transanal endoscopic microsurgery (TEM). J R Coll Surg Edinb 38(4): 239-245.

2. Kuwano S, Fujita T, Pan D, Wang K, Chen M (2008) TEM sample preparation for micro compressed nanocrystalline Ni. Mater Trans 49(9): 2091-2095.

3. Langford RM (2006) Focused ion beams techniques for nanomaterials characterization. Microsc Res Tech 69(7): 538-549.

4. Dieterle L, Butz B, Müller E (2011) Optimized Ar(+)-ion milling procedure for TEM cross-section sample preparation. Ultramicroscopy 111(11): 1636-1644.

5. Giannuzzi LA, Stevie FA (1999) A review of focused ion beam milling techniques for TEM specimen preparation. Micron 30(3): 197-204.

6. Howitt DG (1984) Ion milling of materials science specimens for electron microscopy: A review. J Elec Micros Tech 1(4): 405-414.

7. Mayer J, Giannuzzi LA, Kamino T, Michael J (2007) TEM sample preparation and FIB-induced damage. MRS bull 32(05): 400-407.

8. Sáfrán G, Szász N, Sáfrán E (2015) Two-In-one sample preparation for plan-VIew TEM. Microsc Res Tech 78(7): 599-602.

9. Williams DB, Carter CB (2009) Transmission Electron Microscopy. ( $2^{\text {nd }}$ edn), Springer, New York, USA. 
This work is licensed under Creative Commons Attribution 4.0 Licens

DOI: 10.19080/JOJMS.2017.02.555576
Your next submission with Juniper Publishers will reach you the below assets

- Quality Editorial service

- Swift Peer Review

- Reprints availability

- E-prints Service

- Manuscript Podcast for convenient understanding

- Global attainment for your research

- Manuscr ipt accessibility in different formats

( Pdf, E-pub, Full Text, Audio)

- Unceasing customer service

Track the below URL for one-step submission https://juniperpublishers.com/online-submission.php 